\title{
Do doctors recognise eating disorders in children?
}

\author{
Rachel J Bryant-Waugh, Bryan D Lask, Rosamund L Shafran, Abe R Fosson
}

\begin{abstract}
The aim of this study was to determine whether doctors recognise eating disorders in children, in particular anorexia nervosa. A group of paediatricians, general practitioners, and school medical officers was approached to participate in the study. Each was sent a questionnaire including two case vignettes of children with anorexia nervosa and questions about diagnosis and management. The response rate was $64.5 \%$. Of 97 different diagnoses suggested, only one quarter were psychiatric or psychological. One third of the paediatricians mentioned anorexia nervosa within their differential diagnosis in both cases compared with $2 \%$ of primary care physicians. These results suggest that doctors' awareness of childhood onset eating disorders remains limited. A delay in appropriate treatment has potentially adverse consequences for prognosis.
\end{abstract}

Families of children with an eating disorder may spend many months consulting a variety of health professionals before being referred to child psychiatry. We found an average period of $7 \cdot 4$ months between parents first seeking advice about eating problems and referral to our clinic. ${ }^{1}$ Often this delay appears due to the doctors consulted failing to recognise the eating disorder. We believe this frequently impedes our ability to provide effective treatment as the eating disorder becomes more entrenched and parents focus on medical instead of emotional/ behavioural issues. In older patients with an eating disorder, a shorter history of illness before treatment has been found to be a predictor of good outcome. ${ }^{2-5}$ By implication, a delay between onset and treatment may be unfavourable in terms of prognosis. We therefore addressed the question: Do doctors consider a diagnosis of eating disorder in children? This is a prerequisite to early intervention.

The epidemiological literature suggests that it is difficult to identify eating disorders at a primary care level as prevalence rates are low, especially for children. ${ }^{6}$ Nevertheless, we have seen an increase in the number of children referred for treatment of an eating disorder over the past decade; most receive a diagnosis of anorexia nervosa but some are diagnosed as having 'food avoidance emotional disorder"7 or more idiosyncratic forms of food refusal ${ }^{8}$ or selective eating patterns. As anorexia nervosa is the most commonly encountered formally diagnosable eating disorder in the population we serve (8-14 years), this was the focus of the study.
The aims of the study were to: (1) Discover to what extent 'anorexia nervosa' in particular and 'eating disorder' in general are considered possible diagnoses in children. (2) Discover how likely doctors are to consider a psychological explanation for presenting eating difficulties and to ascertain what effect this has on management. (3) Identify the existence of any common patterns of management and referral of such children. (4) Determine whether there appear to be any differences between primary care doctors and paediatricians in the above respects.

\section{Methods}

All paediatricians and school doctors and a random selection of one general practitioner from each of a number of group practices listed within a defined geographical region were approached. Of these 140 doctors, 56 (40\%) were paediatricians, $38(27 \%)$ school medical officers, and $46(33 \%)$ general practitioners. All were sent a four page questionnaire and a signed covering letter omitting detail of title, post, or profession.

The questionnaire included two short case vignettes based on children seen at our eating disorders clinic, describing common presenting features of children with anorexia nervosa. The first concerned an 11 year old girl experiencing abdominal pains, nausea, and occasional vomiting for the previous three months after a urinary tract infection treated with antibiotics. Because of these symptoms she had not felt like eating and agreed that she had lost weight. Previously of average weight and height for her age, she had lost $10 \mathrm{~kg}$. Examination reveals only that she is thin and complaining of generalised tenderness in the abdomen.

The second case concerned an 11 year old boy about whom there had been concern regarding weight loss, although he considered himself well. Also of average weight and height for his age previously, he had lost $10 \mathrm{~kg}$ over the past three months. He had become moody, withdrawn, and fussy about meals, eating a restricted range of foods very slowly. On examination he is very thin but no other significant abnormality can be found.

Doctors were asked to suggest a provisional diagnosis and two differential diagnoses for each of the two cases. Using a given scale, they then rated a series of management options in terms of how likely they would be to implement them initially. Finally, the doctors indicated further steps if the results of blood and urine tests undertaken proved normal.

Statistical analysis was by $\chi^{2}$ which was
Correspondence and requests for reprints to:
Dr Bryant-Waugh.

Accepted 20 September 1991 
corrected for continuity using Yates's procedure. Where this differed from the uncorrected value, Fisher's exact test was carried out.

\section{Results}

DIAGNOSIS

Two letters were returned unopened and 89 of the 138 potential responders $(65 \%)$ replied. Of these, $33(60 \%)$ of the paediatricians returned completed questionnaires compared with 46 $(55 \%)$ of general practitioners and school doctors (not significant: $\chi^{2}=0.13, \mathrm{df}=1, \mathrm{p}>0.05$ ). Data from one paediatrician who had been practising as a geneticist were excluded. As many school doctors also worked as general practitioners, data from these primary care physicians were combined.

Some doctors gave more than one provisional and two differential diagnoses and some gave less. In all, 97 different diagnoses were suggested, approximately a quarter of which $(n=25)$ were psychiatric/psychological. Diagnoses relating to gastrointestinal $(n=24)$ and renal $(n=15)$ disorders were other common groups. The remaining 33 diagnoses included a range of disorders.

In addition to anorexia nervosa the psychiatric diagnoses related to eating included food refusal, disorder of eating behaviour, psychogenic anorexia, pyschiatric disturbance with anorexia, and food fetishism, although each of these was mentioned by only one physician. Significantly more paediatricians than primary care physicians suggested anorexia nervosa in each case, yet only $31 \%(n=10)$ of paediatricians and $2 \%$ $(n=1)$ of primary care physicians mentioned it in both cases. Renal disease and gastrointestinal diagnoses were suggested far more frequently than eating related disturbances in case 1 by both groups of doctors (see table 1).
No significant sex differences were found. Of the 54 male respondents and 25 female respondents, $48 \%$ made at least one diagnosis of an eating problem; $44 \%$ of each sex specified anorexia nervosa.

\section{MANAGEMENT}

In both cases the majority indicated that the initial step in management would be to arrange blood and urine investigations, then see the child again (table 2). Early referral to a paediatrician (or paediatric colleague) was also considered by over half of both groups of doctors. In case 1 , referral to a mental health specialist was specified by $16 \%$ of paediatricians and $9 \%$ of the primary care physicians after having seen the child only once; the figures for case 2 were $50 \%$ and $30 \%$ respectively (see table 2 ).

After normal blood and urine test results primary care physicians were significantly more likely than paediatricians to consider referral to a paediatrician or paediatric colleague $\left(\chi^{2}=7 \cdot 811\right.$, $\mathrm{p}<0.01$ ), but this pattern was reversed for referral to other named specialists (see table 2). Referral to a mental health specialist was mentioned by $38 \%$ of paediatricians and $26 \%$ of primary care physicians in case $1\left(\chi^{2}=0.680\right.$, p $>0.05)$ compared with $72 \%$ of paediatricians and $43 \%$ of primary care physicians in case 2 $\left(\chi^{2}=5 \cdot 057, \mathrm{p}<0.05\right)$.

\section{Discussion}

It is, of course, unlikely that a doctor would make a diagnosis on the basis of such limited information as that provided in the case vignettes. However, doctors were not asked for a definitive diagnosis and the aim was to gain an impression of whether an eating disorder might be suspected in children presenting with features of anorexia nervosa accompanied by significant weight loss.

Table 1 Diagnoses: number (\%) of doctors making different types of diagnoses

\begin{tabular}{|c|c|c|c|c|c|c|}
\hline & \multicolumn{3}{|c|}{ Psychiatric } & \multirow[t]{2}{*}{ Renal } & \multirow[t]{2}{*}{ Gastrointestinal } & \multirow[t]{2}{*}{ Other } \\
\hline & $\begin{array}{l}\text { Anorexia } \\
\text { nervosa }\end{array}$ & $\begin{array}{l}\text { Eating } \\
\text { related } \\
\text { disorder }\end{array}$ & Other & & & \\
\hline $\begin{array}{l}\text { Case 1: } \\
\text { Paediatricians } \\
\text { Primary care physicians } \\
\text { Case 2: }\end{array}$ & $\begin{array}{r}13(41)^{*} \\
6(13)^{*}\end{array}$ & $\begin{array}{l}2(6) \\
1(3)\end{array}$ & $\begin{array}{r}7(22) \\
15(33)\end{array}$ & $\begin{array}{l}27(84) \\
41(90)\end{array}$ & $\begin{array}{l}18(56) \\
20(43)\end{array}$ & $\begin{array}{l}17(53) \ddagger \\
32(70) \ddagger\end{array}$ \\
\hline $\begin{array}{l}\text { Paediatricians } \\
\text { Primary care physicians }\end{array}$ & $\begin{array}{l}18(56) \dagger \\
9(20) \dagger\end{array}$ & $\begin{array}{l}2(6) \\
1(3)\end{array}$ & $\begin{array}{l}11(34) \\
30(65)\end{array}$ & $\begin{array}{r}3(11) \\
11(24)\end{array}$ & $\begin{array}{r}8(25) \\
14(30)\end{array}$ & $\begin{array}{l}18(56) \\
31(67)\end{array}$ \\
\hline
\end{tabular}

${ }^{*} \chi^{2}=6.367, \mathrm{p}<0.05 ;+\chi^{2}=9.659, \mathrm{p}<0.01 ; \ddagger \chi^{2}=7.850, \mathrm{p}<0.01$.

Total paediatricians, $n=32$, and primary care physicians, $n=46$

Table 2 Management: number (\%) of doctors making different management decisions

\begin{tabular}{|c|c|c|c|c|c|c|c|c|c|}
\hline & \multicolumn{5}{|l|}{ Initially } & \multicolumn{4}{|c|}{ After normal test results } \\
\hline & \multirow[t]{2}{*}{$\begin{array}{l}\text { Blood/urine } \\
\text { tests }\end{array}$} & \multirow[t]{2}{*}{$\begin{array}{l}\text { Refer to } \\
\text { paediatrician }\end{array}$} & \multicolumn{3}{|c|}{$\begin{array}{l}\text { Refer to other } \\
\text { specialist }\end{array}$} & \multirow[t]{2}{*}{$\begin{array}{l}\text { Refer to } \\
\text { paediatrician }\end{array}$} & \multicolumn{3}{|c|}{$\begin{array}{l}\text { Refer to other } \\
\text { specialist }\end{array}$} \\
\hline & & & Unspecified & $\begin{array}{l}\text { Mental } \\
\text { health }\end{array}$ & Other & & Unspecified & $\begin{array}{l}\text { Mental } \\
\text { health }\end{array}$ & Other \\
\hline $\begin{array}{l}\text { Case 1: } \\
\text { Paediatricians } \\
\text { Primary care physicians } \\
\text { Case 2: }\end{array}$ & $\begin{array}{l}27(84) \\
37(80)\end{array}$ & $\begin{array}{l}19(59) \\
33(72)\end{array}$ & $\begin{array}{r}8(25) \\
12(26)\end{array}$ & $\begin{array}{l}5(16) \\
4(9)\end{array}$ & $\begin{array}{l}4(13) \\
9(20)\end{array}$ & $\begin{array}{l}19(59)^{*} \\
41(89)^{*}\end{array}$ & $\begin{array}{r}4(13) \\
10(22)\end{array}$ & $\begin{array}{l}12(38) \\
12(26)\end{array}$ & $\begin{array}{l}6(19) \\
5(11)\end{array}$ \\
\hline $\begin{array}{l}\text { Paediatricians } \\
\text { Primary care physicians }\end{array}$ & $\begin{array}{l}26(81) \\
33(72)\end{array}$ & $\begin{array}{l}17(53) \\
24(52)\end{array}$ & $\begin{array}{l}7(22) \\
8(17)\end{array}$ & $\begin{array}{l}16(50) \\
14(30)\end{array}$ & $\begin{array}{l}\mathbf{0} \\
\mathbf{0}\end{array}$ & $\begin{array}{l}19(59) \\
37(80)\end{array}$ & $\begin{array}{c}2(6) \\
10(22)\end{array}$ & $\begin{array}{l}23(72) \dagger \\
20(43) \dagger\end{array}$ & $\begin{array}{l}\mathbf{0} \\
\mathbf{0}\end{array}$ \\
\hline
\end{tabular}

${ }^{*} \chi^{2}=7 \cdot 811, p<0 \cdot 01 ;+\chi^{2}=5 \cdot 057, p<0 \cdot 05$.

Total paediatricians, $n=32$, and primary care physicians, $n=46$. 
Results suggest that, in general, paediatricians are more likely than primary care physicians to consider a diagnosis of eating disorder in children presenting with eating problems and weight loss. Only one third of paediatricians (31\%) questioned the possibility of anorexia nervosa in both cases, compared with a mere $2 \%$ of primary care physicians. In the case of presentation after a urinary tract infection, the number of doctors suggesting anorexia nervosa was especially low. This presentation may appear quite atypical and it is acknowledged that urinary tract disease is more common than eating disorder. However, it is not unusual for eating disorders to present with a wide range of physical symptoms masking the underlying psychopathology and limiting the physician's ability to identify eating disorders in the early stages. ${ }^{9}$

It has been suggested that general practitioners may have a low index of suspicion for eating disorders and are poor at recognising eating disorders or making a link between psychological problems and eating difficulties, impeding effective treatment. ${ }^{10-11}$ The results of this study appear to support these general findings.

In terms of management, basic blood and urine screening was the most usual preferred step. About half of both groups of doctors indicated that they would see the child at least three times before referring them on. This did not appear to be related to diagnosis, suggesting that where an eating disorder might be suspected, early referral to mental health colleagues may not occur. The tendency for general practitioners not to refer their patients with eating disorders has been reported elsewhere. ${ }^{12}$

In this study, after normal test results primary care physicians showed a significantly greater tendency to refer to paediatricians than the group of paediatricians did to refer to paediatric colleagues. In turn, paediatricians showed a non-significantly greater tendency than the primary care physicians to refer to another specialist.

One of the further aims of the study was to determine the extent to which a psychological basis was considered. It can be extrapolated from the numbers of doctors making a psychiatric/psychological diagnosis. Paediatricians did so at slightly higher rates than primary care physicians, which is presumably related to their higher tendency to refer to mental health specialists.

In conclusion, these findings appear to show that physicians' awareness of childhood onset eating disorders remains rather limited, particularly that of primary care physicians. This is of some concern given that children are most likely to present to these doctors in the early stages of their eating disorder. Although more inclined to consider a diagnosis of anorexia nervosa, the majority of paediatricians made no mention of any eating disorder in at least one of the two cases. We conclude, therefore, that the diagnosis of eating disorder may often be missed in young children, resulting in a delay in the initiation of appropriate treatment and a possible poor effect on prognosis.

We would like to thank the Society for the Advancement of Research into Anorexia (SARA) for their generous financial support.

1 Fosson A, Knibbs J, Bryant-Waugh R, Lask B. Early onset anorexia nervosa. Arch Dis Child 1987;62:114-8.

2 Morgan HG, Russell GFM. Values of family background and clinical features as predictors of long term outcome in anorexia nervosa: four year follow-up study of 41 patients. Psychol Med 1975;5:355-71.

3 Pierloot RA, Wellens W, Houben ME. Elements of resistance to a combined medical and psychotherapeutic program in to a combined medical and psychotherapeutic program

4 Hsu LKG, Crisp AH, Harding B. Outcome of anorexi nervosa. Lancet 1979; i:61-5.

5 Theander S. Long term prognosis of anorexia nervosa: a preliminary report. In: Darby PL, Garfinkel PE, Garner DM, Coscina DV, eds. Anorexia nervosa: recent developments in research. New York: Alan R Liss, 1983:441-2.

6 Wiliams P, King M. The 'epidemic' of anorexia nervosa: another medical myth? Lancet 1987;i:205-7.

7 Higgs JF, Goodyer IM, Birch J. Anorexia nervosa and food avoidance emotional disorder. Arch Dis Child 1989;64: 346-51.

8 Lask B, Britten C, Kroll L, Magagna J, Tranter M. Children with pervasive refusal. Arch Dis Child 1991;66:866-9.

9 American College of Physicians, Health and Public Policy Committee. Eating disorders: anorexia nervosa and bulima. Ann Intern Med 1986;105:790-4.

$10 \mathrm{King} \mathrm{MB}$. Eating disorders in a general practice population. Prevalence, characteristics and follw-up at 12 to 18 months. Prevalence, characteristics and follw-up at
Psychol Med 1989;Monograph suppl 14.

11 Mattingly D, Bhanji S. The diagnosis of anorexia nervosa. $f$ R Coll Physicians Lond 1982;16:191 -4 .

12 Fairburn CG, Cooper PJ. Binge eating, self-induced vomiting and laxative abuse: a community study. Psychol Med 1984;14:401-10. 